\title{
Research on greenhouse intelligent remote control system
}

\author{
Wang-Jun ${ }^{1, a}$, Yu-Haiye $e^{1, a}$ \\ ${ }^{1}$ College of Biological and Agricultural Engineering, Jilin University, Changchun130022,China \\ awangjun_jledu@163.com
}

Keywords: intelligent control, remote control, realtime display, fuzzy control strategy

\begin{abstract}
An intelligent greenhouse remote control system based on $\mathrm{VC}++6.0$ has been designed according to the needs of greenhouse control. The structure of this system is composed of four layers: a remote computer is taken as the client-side, a local computer is taken as the server-side, a singlechip of Stc15f2k60s2 is adopted as the greenhouse controller, a data collection unit and actuators. The environment parameters and actuators running state can be realtime displayed in the remote control software and the opening and closing of actuators in the greenhouse can be manual controlled by remote computer. The local computer monitoring software has the functions of real-time display, data storage, parameter settings and changings, the design of fuzzy control strategy and the status display of actuators, so as to control the environment parameters such as temperature and humidity by setting different temperature value in different period. A more than one month experiment of the system was conducted in the greenhouse, and the results show that the environment parameters such as temperature and humidity can be controlled within the proper scope of plants growth, and create a good environment for plants.
\end{abstract}

\section{Introduction}

In recent years, control of greenhouse environment and crop cultivation management is developing towards intelligentize[1] and network[2], greenhouse industry is developing in the direction of energy saving[3] and sustainability[4], energy saving technology becomes the research focus[5].

The base temperature and temperature changing in Jilin area compared with other areas are quite different. The existing control system can't be changed along with the change of user requirements and seasonal change. So it's very necessary to research a kind of greenhouse control system suitable for local demand with the function of remote control.

\section{Hardware constitution of greenhouse intelligent remote control system}

The whole system is made up of a remote control computer、a local computer and many lower computers which control multiple greenhouses by choosing a different serial port.

The local computer uses a greenhouse intelligent control software established by Visual C ++ 6.0. It can

accept data transferred from lower computer、 compare with the set value, and then send control instructions to lower computer through the intelligent control decisions to realize the control of the actuators. 
A singlechip of Stc15f2k60s2 is adopted as the greenhouse controller which has the function of communicating with both local computer and underlying nodes. Data collection unit consists of temperature and humidity sensor、Light sensor and Carbon dioxide concentration sensor and actuators including outside sunshade 、 inside sunshade 、 interior thermal insulation 、 roof-window, wet curtain eversion window 、 exhaust fan 、 circulation fan 、 air-condition、 light-compensating lamp、carbon-dioxide generator and wet curtain pump.

The remote control computer installed a remote control software established by Visual C ++6.0 , input the web address of local computer in greenhouse remote control software of remote computer, when network connection is successful, the environment parameters and actuators running state can be realtime displayed in the remote control software and the opening and colsing of actuators in the greenhouse can be manually controlled by remote computer.

\section{Software design of greenhouse intelligent remote control system}

Design of greenhouse remote control software

Greenhouse remote control software is based on TCP/IP client/server mode and connection-oriented streaming socket. A remote control computer is taken as the client-side, a local computer is taken as the server-side. The client and server must establish communication socket, first the server should be into the listening state, the client socket sends connection requests, then server communicates with the socket original responsible for listening when it receives requests. The server supports only one client for remote operation at the same time.

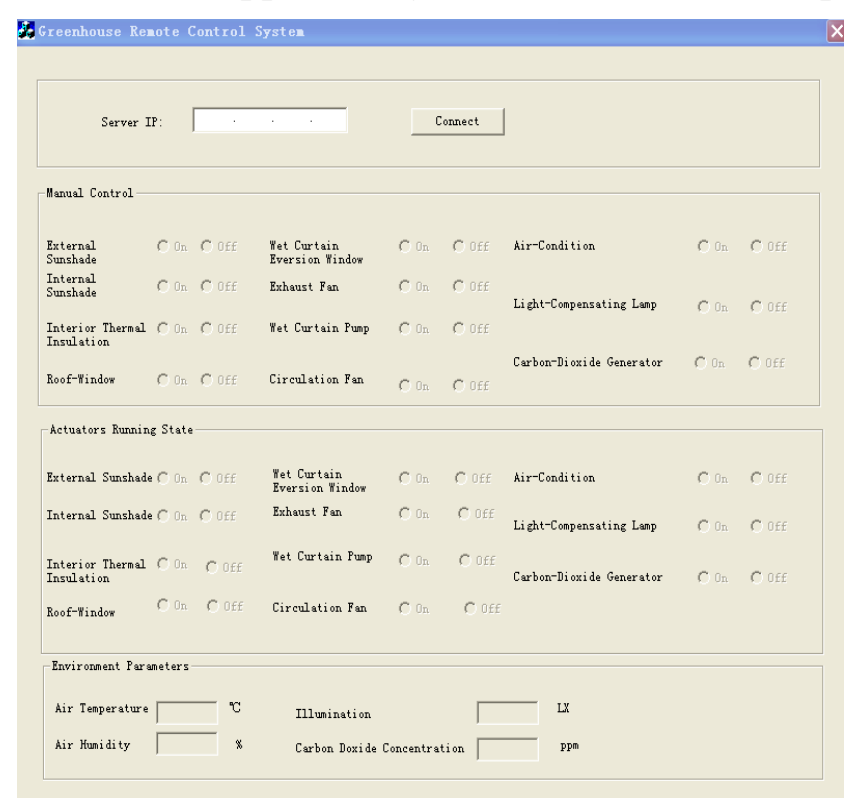

Fig.1 Main interface of remote control software

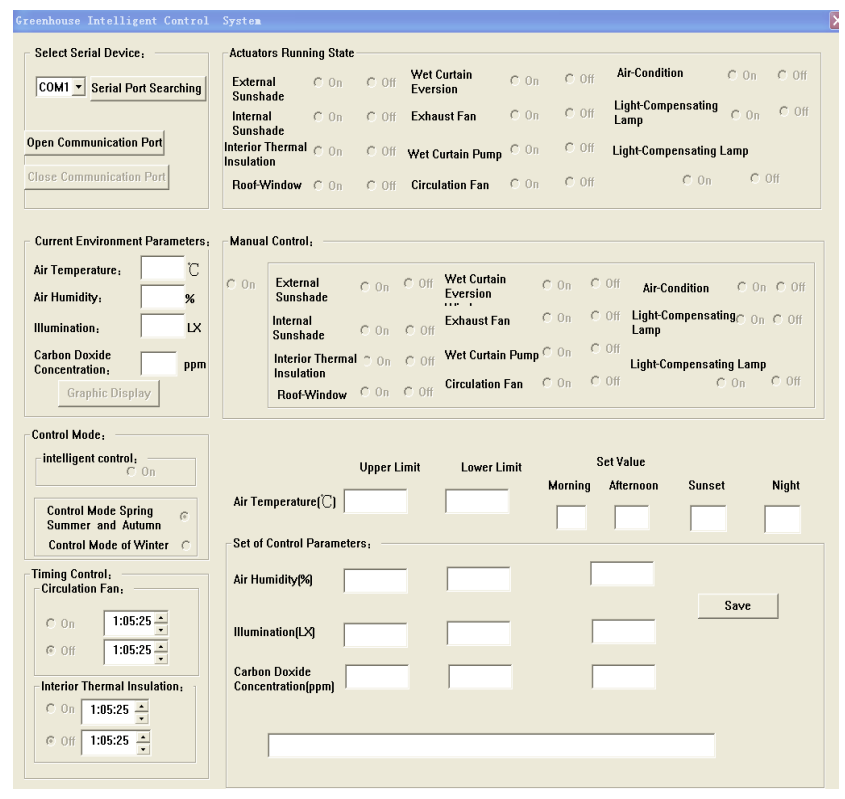

Fig.2 The main interface of intelligent control system

Main interface of remote control software is shown in Figure 1, the software can realtime display temperature , humidity illumination $、 \mathrm{CO}_{2}$ concentration and the actuators running state of greenhouse and manually control the opening and colsing of actuators in the greenhouse. So greenhouse can be real-time monitored in remote or different place, we can also timely close actuators such as roof-window when meet strong wind or heavy rain, then the manpower is saved and the normal operation of the greenhouse is ensured.

Design of greenhouse intelligent control software

The main interface of intelligent control system is shown in Figure 2. The software is composed of six modules of different function: human-computer interaction interface module is used to 
achieve system landing and password management; Data receiving display module is used for realtime numerical and graphic display of environment parameters including temperature 、 humidity villumination and $\mathrm{CO} 2$ concentration of greenhouse, storage of data received from greenhouse controller, and over-limit alarm. Parameters setting module can be used to set environment parameters according to different needs of different plants so as to provide appropriate growth environment for plants;Control strategy module is used for analyzing and processing data information received from greenhouse controller and provides intelligent automatic control or manual control for the greenhouse ; Status display module can real time display running status of actuators ; Communication module fulfills the setting of communication protocol and receiving and sending of data.

Design of greenhouse controller software

The software development environment is Keil uVision4 using $\mathrm{C}$ language as programming language. Greenhouse controller is responsible for collecting parameters information such as temperature and humidity, and transmitting parameters information to local computer for analysis processing, then receiving control instruction from local computer to realize the control of actuators.

\section{The design of control strategy}

The controlled environment parameters including temperature, humidity illumination and $\mathrm{CO}_{2}$ concentration of greenhouse. Due to the interaction between the controlled variables, an environmental factor changed affects the change of other environmental factors, a multi-factor comprehensive control strategy should be used, the control mode can be divided into two which are spring summer autumn mode and winter mode. The control time of the day is also divided into four periods which are morning, afternoon 、sunset and night using different temperature setting value. To avoid the frequent opening and closing of actuating motor, every 30 min environment factor data is as input sampling data.

When the various environmental factors achieve higher or lower than the upper or lower limit, prompt manual operation all can be alarmed. Illumination which ideal value is 30000lx is adjusted by opening and closing outside sunshade 、 inside sunshade and light-compensating lamp. Turn on circulation fan at 6 every morning for half an hour to keep the greenhouse climate more uniform. In winter, open interior thermal insulation at 17 every afternoon and tuck it at 8 the next morning to make the greenhouse heat preservation at night.

As for spring summer autumn mode, due to the interaction between temperature and humidity, so the temperature and humidity combined control strategy is taken. Humidity is divided into 3 levels to high $(>80 \%$ )、 middle (between $70 \%$ and $80 \%$ ) and $(<70 \%)$. The temperature control using fuzzy control strategy to control roof-window, wet curtain eversion window v exhaust fan and wet curtain pump.

The winter here mainly refers to time from the beginning to the end of the heating period. At daytime(6:00-18:00), turn off the air condition when temperature is above $35^{\circ} \mathrm{C}$ and turn on the air condition when temperature is below $20^{\circ} \mathrm{C}$. At night(18:00-6:00), turn off the air condition when temperature is above $20^{\circ} \mathrm{C}$ and turn on the air condition when temperature is below $10^{\circ} \mathrm{C}$.

\section{System running test and analysis}


The experimental greenhouse is in Nanling Campus of Jilin University. About $200 \mathrm{~m}^{2}$,an all-glass one, with the side windows on the four side available to be opened manually. The test time is from May $17^{\text {th }}, 2014$ to June $19^{\text {th }}, 2014$.

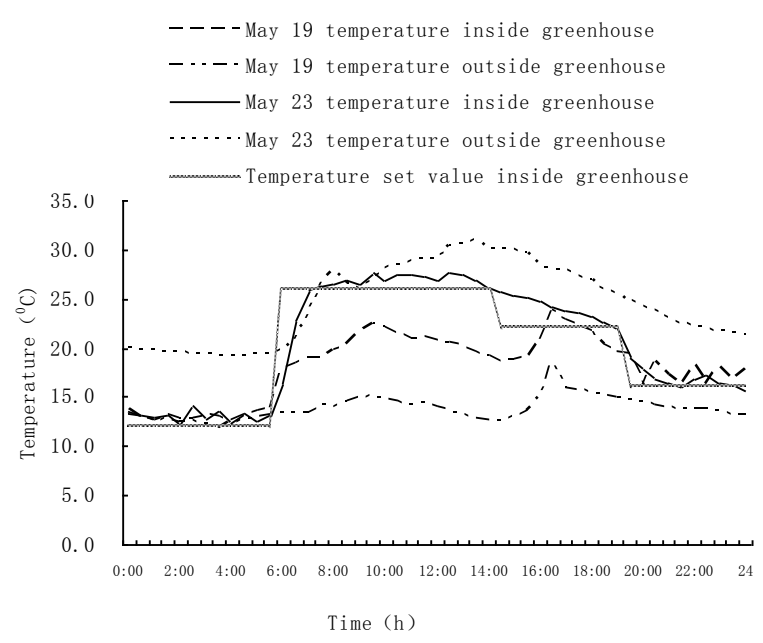

Fig. 3 The comparison diagram of set value and temperature inside and outside greenhouse

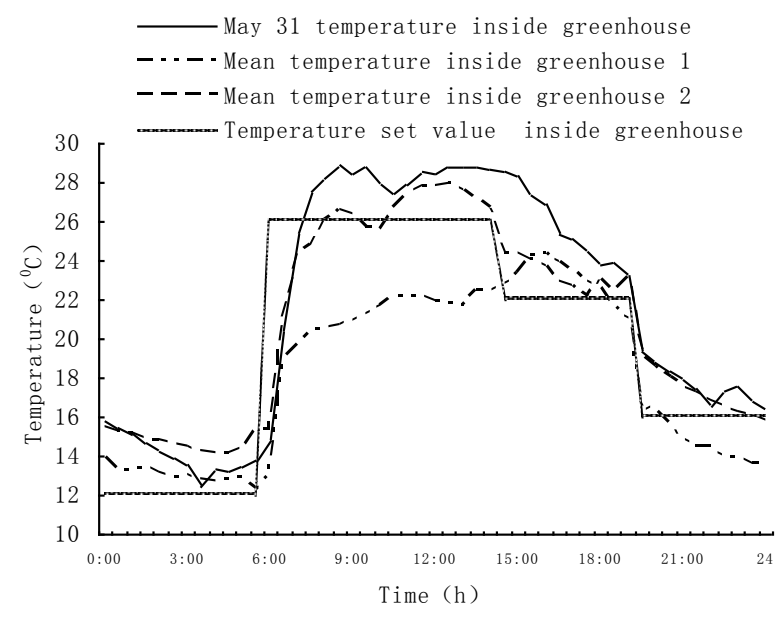

Fig.4 The comparison diagram of set value and temperature inside greenhouse

The comparison diagram of set value and temperature inside and outside greenhouse of May $19^{\text {th }}$ and May 23 is shown as figure 3. The comparison diagram of set value and temperature inside greenhouse is shown as figure 4. At day of May $19^{\text {th }}$ 、 May 23 and May 31, the greenhouse is monitored by intelligent control strategy for 24 hours. During other days ,only from 8 am to 19 pm the greenhouse is monitored by intelligent control strategy, other time the greenhouse roof-window and side windows are open for natural ventilation according to temperature in the greenhouse. Mean temperature inside greenhouse 1 is the mean temperature of 7 days whose temperature is lower during morning, mean temperature inside greenhouse 2 is mean temperature of other days. From the figures we know that when temperature outside the greenhouse is very high such as up to $22-33^{\circ} \mathrm{C}$ on May 31, temperature inside greenhouse all can be controlled in the suitable temperature range of the growth of the cucumber, temperature variation and temperature set value change is consistent. But when temperature outside the greenhouse is low, then temperature inside greenhouse is lower than set value about $3-7^{0} \mathrm{C}$, it's harm to cucumber growth, so temporary heating measures such as turning on air condition should be taken.

\section{Conclusion}

The experimental results shows that the system is user-friendly and easy operation, it can achieve realtime display of environment parameters and actuators running state and intelligent control of the greenhouse environment according to the control strategy. In addition, the system is easy to change the control parameters such as temperature and humidity so as to adapt different needs of plants, and it's convenient for technicians or managers to monitor and control the greenhouse environment and running status of actuators from remote computer in different province or city or even in different country, so as to achieve the purpose of staff reduction and efficiency increasing.

\section{References}

[1]Zhan Mei,Liu Chunhong,Wei Yaoguang,etal. Design of Wireless Intelligent Monitoring System for Greenhouse Temperature and 
Humidity Based on Fuzzy Control[J]. Agricultural Engineering, 2013,3(3):47 50 .

[2]Wang Jun,Liu Gang. Method of energy saving based on particle swarm optimization clustering for greenhouse wireless sensor networks[J].Transactions of the Chinese Society of Agricultural Engineering, 2012,28(7):172 177.

[3]Diane Bastien, Andreas K Athienitis. A control algorithm for optimal energy performance of a solarium/greenhouse with combined interior and exterior motorized shading [J]. Energy Procedia,2012, $30: 995 \sim 1005$.

[4]Salwa Bouadila, Mariem Lazaar, Safa Skouri,etal. Assessment of the greenhouse climate with a new packed-bed solar air heater at night, in Tunisia[J]. Renewable and Sustainable Energy Reviews, $2014,35: 31 \sim 41$.

[5]I Attar, N Naili, N Khalifa,etal. Experimental study of an air conditioning system to control a greenhouse microclimate[J]. Energy Conversion and Management , 2014, $79: 543 \sim 553$. 